\title{
RELAÇÃO HOMEM-NATUREZA-POLÍTICA: UM PARALELO ENTRE ROUSSEAU E FEUERBACH ${ }^{1}$
}

\author{
Manoel Jarbas Vasconcelos Carvalho ${ }^{2}$
}

\begin{abstract}
Resumo:
O objetivo principal deste trabalho consiste em compreender como os termos "homem", "natureza" e "política" estão relacionados no pensamento de Rousseau e Feuerbach. A finalidade de tal proposta é revelar como esses termos são basilares no pensamento dos dois autores e o seu propósito primacial é mostrar a íntima relação entre a filosofia de ambos. Para tanto, faz-se importante conhecer quatro momentos essenciais que tornam possível este diálogo, a saber: 1) A crítica aos dogmas do Cristianismo como responsáveis pela separação entre homem e natureza; 2) A antropologia como principal objeto de estudo dos dois pensadores e o elo que os une definitivamente; 3) A construção de uma genealogia histórica que explique como se constitui o homem na condição de ser político e como, nesse processo, ele se separa de sua vida comunitária; 4) $\mathrm{O}$ restabelecimento da política como exigência necessária para a harmonia perdida entre o homem e a natureza.
\end{abstract}

Palavras-chaves: Homem. Natureza. Política. Rousseau. Feuerbach.

\section{THE RELATION AMONG MAN-NATURE-POLITICS: A PARALLEL BETWEEN ROUSSEAU AND FEUERBACH}

\begin{abstract}
:
The main goal of this work is to understand how the terms "man", "nature" and "politics" are related in the thought of Rousseau and Feuerbach. The purpose of this proposition is to reveal how these terms are basic in the thinking of this two authors and also to show the intimate relation between theirs philosophies. For this, it is important to know four essential moments that make this dialogue possible, namely: 1) The criticism of the dogmas of Christianity as responsible for the separation between man and nature; 2) Anthropology as the main object of study for them and as the link that definitively unites them; 3) The construction of a historical genealogy that explains how man is constituted as a condition for the political bean and how, during this process, he separates himself from his community life; 4) The reestablishment of the politics as a necessary requirement for the harmony that was lost between man and nature.
\end{abstract}

Keywords: Men. Nature. Politics. Rousseau. Feuerbach.

1 Este texto é resultado de pesquisas realizadas no Estágio Pós-doutoral em Filosofia na Universidade Federal do Rio Grande do Norte - UFRN sob a supervisão do professor Doutor Antônio Basílio Novaes Thomaz Menezes.

2 Doutor em Educação com ênfase em Filosofia da Educação pela Universidade Federal do Ceará (UFC). Mestre em Ética e Filosofia Política e Graduado em Filosofia pela Universidade Estadual do Ceará (UECE). Editor gerente da Revista Dialectus - Revista de Filosofia da Universidade Federal do Ceará (Qualis B3). Associado a ABES XVIII (Associação Brasileira de Estudos do Século XVIII) e a SIEDS (Société Internationale d'Étude du Dix-huitième Siècle). E-mail: jarbasvc@gmail.com. 


\section{RELAĈ̃O HOMEM-NATUREZA-POLÍTICA: UM PARALELO...}

Manoel Jarbas Vasconcelos Carvalho

\section{A CRítiCA AOS DOGMAS DO CRISTIANISMO EM ROUSSEAU E FEUERBACH: UMA INTRODUÇÃO.}

É possível pontuarmos diversos desacordos entre Rousseau e Feuerbach, porém não é nossa intenção fazermos isso neste artigo, ao contrário, nosso propósito é revelar pontos em comum consoante o pensamento político desses dois autores. Uma importante ligação entre ambos é a crítica ao Cristianismo. O estranhamento do homem no tocante à natureza passa pela abstração de um Deus que não é mais visto por ele como um ser natural. Nesse sentido, os valores de uma vida simples e comunitária, em harmonia com a natureza, perderam-se no processo de cristianização da humanidade. Ao identificar-se com Deus, o homem passou a enxergar-se também como um ser acima da natureza. O que houve, a partir de então, foi um processo de inversão dos valores, antes naturais e harmônicos, agora artificiais e distantes da natureza. Deus, visto como um monarca, serviu aos governos - e aos seus governantes - como justificativa da centralidade do poder político, pois somente um ser acima de tudo e de todos pode servir de modelo ao déspota. As principais consequências disso foram a opressão política e a retórica vazia do cosmopolitismo dos Estados, duramente criticadas por Rousseau e Feuerbach.

Os mistérios de Deus ultrapassam a inteligência humana, pensa Rousseau; é inútil ou maldosa a finalidade da religião cristã em querer demonstrá-los. "Todo homem, seja qual for a sua religião, que afirma acreditar em tais mistérios mente ou não sabe o que diz", pontua o genebrino (ROUSSEAU, 1958, p. 243). Conforme Derathé (2011), Rousseau rejeita todos os mistérios da cristandade e acredita que o Evangelho está pleno de coisas que repugnam a razão. A religião cristã, através dos seus dogmas, manipula os ensinamentos de Cristo pelo significante da linguagem. Submetido desde cedo aos mistérios da fé, o homem enxerga apenas o significante do discurso religioso, e não os seus conteúdos concretos (o significado). Assim, estimulado pela imaginação, o homem se acha obrigado a imitar, com seus gestos de fé, uma ordem externa; esta articulada. De imediato, ele, o fiel, é levado a reproduzir (mas mal) o discurso religioso. Ei-lo assujeitado, à sua revelia, ao significante e a um significante. O problema disso, avalia Rousseau, é que o homem, em seu ato de fé, não costuma ligar a ideia a um sentido; ele encontra o significante no seu arbitrário, e este arbitrário é vivido por ele como uma lei.

\begin{tabular}{|l|l|l|l|l|}
\hline Qevista Dialectus & Ano 5 & n. 12 & Janeiro - Julho 2018 & p. 209-222 \\
\hline
\end{tabular}




\section{RELAĈ̃O HOMEM-NATUREZA-POLÍTICA: UM PARALELO... Manoel Jarbas Vasconcelos Carvalho}

A metafísica do discurso religioso, que descola o significante do seu significado, é proveniente do desligamento do homem de sua realidade imediata, em particular, e de sua natureza, em geral. Esse assujeitamento ao significante experimentado pelo homem elimina aquilo que resta nele de puro e natural, aquilo pelo qual sua natureza se exprime, ou seja, a pureza despretensiosa de suas ações e a bondade de seus atos. Essa alienação do ser humano ao arbitrário do significante tem consequências funestas para a comunidade. A mais imediata delas é a opressão política. A dualidade existente no interior do Estado entre o universalismo cosmopolita do reino de Deus e o poder temporal da Igreja, além de confundir os indivíduos, submete-os ao poder violento dessa última. Rousseau (1999c) assevera que esse dualismo converte o padre no senhor dos homens - exatamente porque ele é o portador do significante - e o transforma em um ser semelhante ao mais violento dos déspotas.

Feuerbach (2009a, p. 24), para quem a crítica aos mistérios de Deus não é menos rigorosa, no Prefácio à segunda edição d'A Essência do Cristianismo, afirma que "A religião é o sonho do espírito humano. [...] o brilho arrebatador da imaginação e da arbitrariedade". Nas Preleções sobre a Essência da Religião, Feuerbach (2009b, p. 211) realça que o Deus da cristandade é um produto da imaginação, um ser espiritual e impalpável baseado no caráter abstrato da palavra: "Em síntese, a essência do Deus cristão, espiritual enquanto um ser que não é captável pelos sentidos, que revela sua própria essência não na natureza ou na arte, mas na Sagrada Escritura, nada mais nos apresenta além da essência da palavra". Os teólogos, assim como os filósofos especulativos, assinala Feuerbach (2009b, p. 136), não formam seus conceitos conforme as coisas, mas as coisas conforme seus conceitos: “[...] As coisas na teologia não são pensadas e desejadas porque elas existem, mas elas existem porque são pensadas e desejadas", isto é, para o religioso, complementa Feuerbach (2009b, p. 136), “[...] a ideia, o pensamento não é abstraído de seu objeto, mas o pensamento é o produtor, é a causa do objeto pensado".

Para o autor das Preleções, o Cristianismo promoveu uma radical inversão dos valores, submetendo o indivíduo concreto (real) ao seu conceito genérico. "O homem abstrai da natureza, por meio da faculdade de abstração, o que é semelhante, parecido, comum, separa-o das coisas que se assemelham e que são de igual essência e em seguida o transforma em um ser autônomo, numa essência diversa das coisas" (FEUERBACH, 2009b, p. 136-137). Dessa sobre-elevação do abstrato sobre o concreto,

\begin{tabular}{|l|l|l|l|l|}
\hline Qevista Qialectus & Ano 5 & n. 12 & Janeiro - Julho 2018 & p. 209-222 \\
\hline
\end{tabular}




\section{RELAĊ̃̃O HOMEM-NATUREZA-POLÍTICA: UM PARALELO... Manoel Jarbas Vasconcelos Carvalho}

o Deus ideal dos cristãos - que nada mais é, para Feuerbach, do que a representação abstrata do gênero humano - tornou-se o senhor soberano sobre toda a natureza, ou, por assim dizer, um verdadeiro monarca. Nesse sentido, como quem controla a linguagem domina a verdade, a Igreja tornou-se oficialmente a representante da palavra de Deus entre os homens. A fé cosmopolita que anima a Igreja, sublinha Feuerbach (2009b), elege sua própria razão e impõe sua lógica sobre o mundo. Essa fé serve à tirania, porque é uma garantia do poder temporal (político) da religião sobre os homens, assinala Feuerbach (2009b).

\section{A ANTROPOLOGIA COMO GENEALOGIA HISTÓRICA E CONSTATAÇÃO DO HOMEM ENQUANTO SER POLÍTICO.}

No Prefácio do Segundo Discurso, Rousseau (1999a) afirma que o interesse de sua investigação é o homem. Nessa obra, o genebrino esforça-se por separar o estado de natureza do estado civil, ou seja, separar aquilo que de fato constituía originalmente a natureza humana dos costumes provenientes da vida social. O estado de natureza representa, de acordo com Rousseau (1999a), o "sono da razão", o momento em que o homem vivia exclusivamente de seus instintos de autoconservação e bem-estar.

Contudo, apesar de a razão humana permanecer inativa no estado de natureza, o homem, nesse estágio, possuía duas qualidades distintas de sua limitada instintividade: a primeira é o sentimento natural de piedade; e a segunda, consequência direta da primeira, é que o homem é naturalmente bom. Sobre o primeiro aspecto, alega Rousseau (1999a, p. 47) que "[...] os homens possuem uma repugnância natural por ver perecer ou sofrer qualquer ser sensível e principalmente nossos semelhantes”. No outro aspecto, o homem é bom, visto que só a sociedade, que faz florescer as desigualdades sociais, torna-o mau (ROUSSEAU, 1999a).

Além desses instintos primitivos, Rousseau (1999a) pontua que os homens possuem faculdades naturais que são ativadas em seu convívio social, como a memória, a imaginação, o sentimento moral e a razão. Os homens, ao longo de sua história, são capazes de desenvolver essas qualidades que lhes são intrínsecas, isto é, são propensos à perfectibilidade (ROUSSEAU, 1999a). Porém, a perfectibilidade, que é a faculdade de aperfeiçoar-se, só pode desenvolver-se com a sociabilidade. A convivência com o outro é que trouxe sucessivamente o desenvolvimento de todas as qualidades naturais dos indivíduos, postula Rousseau no Segundo Discurso.

\begin{tabular}{|c|c|c|c|c|}
\hline Revista Dialectus & Ano 5 & n. 12 & Janeiro - Julho 2018 & p. $209-222$ \\
\hline
\end{tabular}




\section{RELAĊ̃̃O HOMEM-NATUREZA-POLÍTICA: UM PARALELO... Manoel Jarbas Vasconcelos Carvalho}

O despertar da sociabilidade significou também o despertar da consciência humana. No início da vida em comunidade, os homens - já conscientes de si próprios e de seus semelhantes - reuniam-se em hordas nômades em busca de comida e segurança recíproca. Nesse momento, explica Rousseau (1999a), surgiram os primeiros sinais da linguagem humana. Passados muitos séculos de aperfeiçoamentos sucessivos das técnicas e do aprimoramento do seu vocabulário, os homens, já estabelecidos na terra, promoveram sua primeira revolução: a convivência familiar. Com essa nova organização social, deu-se início à juventude do mundo (la jeunesse du monde) (ROUSSEAU, 1999a). Esse momento, a meio caminho entre a indolência do selvagem e a atividade petulante do amor-próprio, foi o mais duradouro e a mais feliz época da história humana ${ }^{3}$, consoante Rousseau (1999a).

A partir do momento em que os homens abdicaram de uma vida simples com o seu comércio pouco desenvolvido, suas ferramentas arcaicas e suas roupas com seus enfeites simplórios, eles passaram a ter necessidade do socorro de outras mãos para produzirem para além de suas necessidades imediatas. Assim, desapareceu a igualdade e se instalou a propriedade e a divisão do trabalho com seus respectivos papéis sociais, como: o rico (proprietário) e o pobre (trabalhador) (ROUSSEAU, 1999a). A mudança sensível dos modos de produção primeiro prendeu os homens ao campo, especificamente com a colheita do trigo, e depois os forçou a fundir e a forjar o ferro: "A metalurgia e a agricultura foram as duas artes cujo advento produziu essa grande invenção [...]; foram o ferro e o trigo que civilizaram os homens e perderam o gênero humano" (ROUSSEAU, 1999a, p. 94).

A desigualdade se instaura de modo decisivo com o nascimento da propriedade privada. A partir desse evento, nota Rousseau (1999a), ocorreu uma cisão entre o "ser" e o "parecer". O homem, que antes era livre e independente na natureza, passou a ser subordinado aos seus semelhantes, dos quais se tornou, num certo sentido, seu escravo. Ricos e pobres, embora dependentes, colocaram-se em eterna disputa pelo

\footnotetext{
3 Faguet (1910, p. 48-49) enfatiza que a jeunesse du monde é o primeiro estado social do homem: "Esse primeiro estado social é a idade de ouro da humanidade e aquela onde ela teria cumprido seus verdadeiros interesses. É o estado de natureza, o verdadeiro estado de natureza [...]. Quando Rousseau fala de estado de natureza, é sempre do primeiro estado social que ele fala [...] e todas as vezes que ele fala dos selvagens é ainda assim que ele os compreende. Há o primeiro estado: o homem animal inteligente, vivendo em estado familiar e inocente. Há o segundo estado: o homem de animal se tornou selvagem, quer dizer, vivendo em tribos e moralmente; e o segundo estado, que é o primeiro estado social, é o melhor jamais registrado. É a adolescência ou a juventude do mundo [...]. Uma idade em que o homem individual queria ser aprovado [...]”. Em nossa opinião, quando Rousseau pretende retomar valores genuinamente comunitários na política moderna, por exemplo, é à juventude do mundo que ele se refere.
}

\begin{tabular}{|l|l|l|l|l|}
\hline Q Povista Qialectus & Ano 5 & n. 12 & Janeiro - Julho 2018 & p. 209-222 \\
\hline
\end{tabular}




\section{RELAĊ̃̃O HOMEM-NATUREZA-POLÍTICA: UM PARALELO... Manoel Jarbas Vasconcelos Carvalho}

direito de posse, o que os tornou ainda mais ambiciosos e malvados (ROUSSEAU, 1999a). Percebendo, porém, que a eterna disputa não era vantajosa, por uma série de motivos, o rico "[...] inventou facilmente razões especiosas para fazer com que aceitassem o seu objetivo: 'Unamo-nos', disse-lhes, [...]” (ROUSSEAU, 1999a, p. 100). A astúcia do proprietário fez com que todos corressem aos seus grilhões, crendo assegurar a sua liberdade, pondera Rousseau (1999a). O patrão ofereceu aos seus subordinados leis e instituições seguras que lhes garantissem igualmente o direito de posse e a proteção de sua vida (ROUSSEAU, 1999a).

Percebendo em todo aperfeiçoamento do pacto social a destreza com que os proprietários buscavam garantir suas posses e seus lucros a troco de preservarem uma liberdade enganosa aos seus subordinados, Rousseau (1999a, p. 103) diz que a “[...] máxima fundamental de todo o direito político é que os povos se deram chefes para defenderem sua liberdade, e não para serem dominados". Para ele, um autêntico pacto social ocorre quando o povo escolhe os seus chefes, e não o contrário, contrato pelo qual as duas partes se obrigam à observância da lei nele estipuladas e formam o liame de sua união (ROUSSEAU, 1999a). Contudo, os homens acostumaram-se à servidão, naturalizaram as desigualdades sociais em suas mentes. Olhando apenas para si como indivíduos, esqueceram que um dia foram livres como gênero humano. $\mathrm{O}$ homem selvagem, assevera Rousseau (1999a), não dobra sua cabeça ao jugo que o homem civilizado carrega sem murmurar e prefere a mais tempestuosa liberdade a uma tranquila dominação.

A sociedade já estabelecida sob o domínio do rico proprietário é também uma sociedade intelectualmente avançada; nela se desenvolveram as ciências e as artes, como nos mostra Rousseau no Discurso sobre as Ciências e as Artes, mas também uma religião sofisticada, a exemplo do Cristianismo. Indubitavelmente Rousseau concorda e acredita no Deus cristão, todavia ele se opõe aos dogmas da religião cristã e a seus artifícios para dominar os homens. Como vimos, Rousseau identificou nos mistérios da fé - na divisão entre o significante e o significado - a íntima ligação entre a Igreja e o poder político; essa distinção não apenas serviu para aumentar a dominação do clero sobre a massa de fiéis, como também serviu de fundamento para o Absolutismo das monarquias europeias, haja vista que, conforme entende Rousseau (1999b), quem detém o poder da palavra, além do poder sobre a terra, é o detentor do arbítrio sobre o povo.

\begin{tabular}{|c|c|c|c|c|}
\hline Revista Dialectus & Ano 5 & n. 12 & Janeiro - Julho 2018 & p. $209-222$ \\
\hline
\end{tabular}




\section{RELAĈ̃O HOMEM-NATUREZA-POLÍTICA: UM PARALELO... Manoel Jarbas Vasconcelos Carvalho}

Feuerbach (2009a), diferentemente de Rousseau (1999b), não fez uma genealogia histórica regressando a um puro estado de natureza do homem, porém a antropologia o liga definitivamente à filosofia de Jean-Jacques. Sua preocupação com o homem transforma sua filosofia numa investigação acerca da história humana; n'A Essência do Cristianismo, ele diz que tomou por critério da verdadeira forma literária e didática não o erudito, abstrato e particular, mas sim o homem universal; o homem em geral. Seu objeto principal de investigação é o Cristianismo, é a religião cristã como objeto imediato, cuja essência é o homem (FEUERBACH, 2009a).

Para o pensador alemão, todo indivíduo está relacionado ao seu gênero, por isso o desenvolvimento da história somente pode ser analisado sob o prisma da generalidade humana. Assim como Rousseau, Feuerbach (2009a) faz análise histórica, investigando os desenvolvimentos sucessivos do homem como espécie. Para ele, o primeiro registro da história só é possível quando o homem se torna consciente do mundo, porém essa consciência, adverte o filósofo, não se desenvolve sem a presença do outro: "A consciência do mundo é então proporcionada ao $\mathrm{Eu}$ através da consciência do Tu" (FEUERBACH, 2009a, p. 105).

O despertar da consciência, que é primeiramente consciência do mundo, proporcionado pelo convívio com um outro ser semelhante a mim, indica que somos seres primordialmente comunitários. O outro homem, diz Feuerbach, é a ponte entre mim e o universo, ou seja, é através do outro que me ligo diretamente ao mundo; é a consciência de algo maior do que eu que faz da relação entre o Eu e o Tu algo tão importante.

[...] Eu sou e me sinto como dependente do universo, porque inicialmente me sinto como dependente de outros homens. Se não necessitasse do homem, não necessitaria também do universo. Eu me concilio, me [sic] torno amigo do universo somente através do outro homem. Sem o outro, o universo não seria para mim morto e vazio, mas também sem sentido e sem razão. Somente através do outro torna-se o homem claro para si e consciente de si mesmo, mas somente quando eu me torno claro para mim mesmo torna-seme o universo claro. (FEUERBACH, 2009a, p. 105).

Um homem que existisse somente para si se perderia nulo e indistinto no oceano da natureza; não compreenderia nem a si mesmo como homem nem a natureza como natureza, indica Feuerbach (2009a). Assim, o primeiro objeto do homem deve ser o homem. O sentimento da natureza, o único que nos proporciona a consciência do mundo como mundo, é um produto posterior, porque ele só aparece como um ato da indistinção que o homem faz de si mesmo (FEUERBACH, 2009a).

\begin{tabular}{|l|l|l|l|l|}
\hline Q Rovista Dialectus & Ano 5 & n. 12 & Janeiro - Julho 2018 & p. 209-222 \\
\hline
\end{tabular}




\section{RELAĈ̃O HOMEM-NATUREZA-POLÍTICA: UM PARALELO... Manoel Jarbas Vasconcelos Carvalho}

Feuerbach (2009a) suscita uma distinção entre o saber e a ciência. Ele sublinha que o saber do indivíduo é limitado, mas a ciência é ilimitada. Esta última é um ato conjunto da humanidade. Mesmo o gênio científico de uma época determinada particularizando a ciência - reúne em si as ideias dos gênios passados; mesmo que seja de um modo determinado, individual, sua força não é, pois, uma força isolada. “[...] Espírito, sagacidade, fantasia, sentimento, enquanto distintos da sensibilidade, da razão - todas essas faculdades da alma são forças da humanidade, não do homem enquanto indivíduo, são produtos da cultura, da sociedade humana" (FEUERBACH, 2009a, p. 105-106).

Segundo o autor d'A Essência do Cristianismo, a natureza cria o mundo e o homem o fabrica (FEUERBACH, 2009a). Para o filósofo, fabricar é um conceito genuíno, fundamentalmente humano, é dizer: fabricar não é uma atividade indiferente ao homem, mas é idêntica à sua essência e necessária para ele (FEUERBACH, 2009a). Nesse sentido, o homem - como fabricante do mundo - é o criador da cultura, e essa condição lhe é inescapável.

A cultura é uma realização do gênero humano e representa o desenvolvimento da razão na espécie. Feuerbach (2009a) defende que a razão tem sua essência em si mesma, logo nada tem além de si ou fora de si que possa ser comparado com ela; ela é, portanto, a medida de todas as coisas; “[...] o princípio supremo de todas as hierarquias, princípio este que subordina todas as coisas e seres" (FEUERBACH, 2009a, p. 70). Sendo assim, não havendo razão, conclui Feuerbach (2009a, p. 70), “[...] não há consciência, tudo seria nada, o ser igual ao não ser. Somente a consciência estabelece a diferença entre ser e não ser. Somente na consciência se revela o valor do ser, o valor da natureza".

A mais elevada forma de afirmação de si mesmo, a forma que conduz o homem a um estado de felicidade consigo próprio, é a consciência (FEUERBACH, 2009a, p. 40). É a consciência que carrega a marca da união do indivíduo com o seu gênero. É ela que de fato revela a universalidade da cultura humana e que trabalha para coroar toda a espécie.

O despertar da consciência e o desenvolvimento da razão, no entanto, não evitaram que se criassem mecanismos de dominação do homem sobre o homem. $\mathrm{O}$ filósofo alemão acredita que o Cristianismo - principal instrumento de alienação dos seres humanos - promoveu a separação entre os indivíduos no interior da comunidade

\begin{tabular}{|c|c|c|c|c|}
\hline Q Rovista Dialectus & Ano 5 & n. 12 & Janeiro - Julho 2018 & p. $209-222$ \\
\hline
\end{tabular}




\section{RELAĈ̃O HOMEM-NATUREZA-POLÍTICA: UM PARALELO... Manoel Jarbas Vasconcelos Carvalho}

humana. Assim, numa outra obra, Teses Provisórias para a Reforma da Filosofia, ele afiança que, confiando exclusivamente em Deus, o homem passa a não mais olhar para o seu semelhante, já que "[...] tudo o que ele deve receber de si ou dos outros recebe-o imediatamente de Deus. Confia em Deus, não no homem; dá graças a Deus, e não ao homem" (FEUERBACH, 2002, p. 16).

Ao proclamar Deus como autoridade absoluta e única fonte de verdade para os homens, o Cristianismo promoveu o estranhamento do indivíduo com relação à natureza e com relação ao seu gênero. A religião cristã desconhece a alteridade e a natureza, uma vez que prioriza o reino dos céus em detrimento da realidade natural e da condição humana. Na crença em Deus, o homem cultiva o desejo de ser sobrenatural e independente da natureza. E essa crença o faz crer ser um ser absoluto, livre de determinações e imune aos desejos do outro, ou seja, faz-lhe crer ser ele o próprio Deus.

O desejo de ser infinito como Deus - ilusão criada pelo Cristianismo - fez do homem um ser arrogante com relação à natureza. Assim sendo, ele não se sente ligado a ela, tampouco ao seu semelhante na vida em comunidade. A crença na providência divina prova que o homem pensa ser um ser especial no tocante à natureza. “A providência é um privilégio do homem; ela expressa o valor do homem em contraste com os outros seres e coisas naturais; ela o arranca da conexão universal" (FEUERBACH, 2012, p. 123). A crença no milagre é um exemplo disso. O homem vê na graça uma prerrogativa divina que o afasta das leis da natureza; uma espécie de salvo-conduto frente ao caráter sempre evanescente do reino natural.

Ao ignorar a natureza como seu fundamento como ser vivo e a relação com o outro como fundamento de sua humanidade, o crente afasta-se do seu próximo e do mundo. Dessa maneira, o Cristianismo traz, na pseudovalorização de Deus relativamente ao homem, um desconhecimento da alteridade real e uma supressão da natureza. O Cristianismo é, para Feuerbach (2012), nesse sentido, a religião do egoísmo e do antinaturalismo.

Depois de verificarmos que as críticas aos mistérios da fé são comuns a Rousseau e a Feuerbach, que a antropologia definitivamente os une e que ambos procuram mostrar na história como o homem se constitui como um ser político e como ele perde essa condição, resta a pergunta: é possível uma nova forma de política que possa restabelecer uma relação harmônica entre o homem e a natureza? E, se possível,

\begin{tabular}{|l|l|l|l|l|}
\hline Q Rovista Qialectus & Ano 5 & n. 12 & Janeiro - Julho 2018 & p. 209-222 \\
\hline
\end{tabular}




\section{RELACÃO HOMEM-NATUREZA-POLÍTICA: UM PARALELO... \\ Manoel Jarbas Vasconcelos Carvalho}

como isso ocorreria? Quais são os instrumentos para tal mudança? Qual a crença política de ambos?

\section{A RELAÇÃO HOMEM-NATUREZA-POLÍTICA EM ROUSSEAU E FEUERBACH: UMA SÍNTESE.}

Com o tema a Relação homem-natureza-política: um paralelo entre Rousseau e Feuerbach apresentamos um lócus privilegiado para refletirmos em torno das questões fundamentais da ética e da filosofia política a partir dos autores mencionados. Portanto, o arcabouço teórico rousseauniano e feuerbachiano nos é essencial. A obra desses pensadores é, por isso, lugar único para debatermos e refletirmos sobre temáticas como: a crítica ao dogmatismo religioso; a constituição do homem político; a relação entre o homem e o meio natural; a alienação dos indivíduos da vida pública; e as novas formas de organização política no âmbito da democracia em seu sentido amplo. Isto posto, Rousseau e Feuerbach nos trazem reflexões que nos são contemporâneas e que dão um sentido de atualidade, e porque não dizer, de originalidade, a este escrito.

Rousseau e Feuerbach viveram em países e em momentos históricos

distintos. Aparentemente nada os liga, haja vista que Rousseau foi um crítico sagaz das teses materialistas de seus contemporâneos e não há indícios de que Feuerbach tenha lido as obras de Rousseau. Nesse contexto, de fato parece-nos inconciliável pensarmos relações comuns entre o teísta Rousseau e o ateu e materialista Feuerbach. Entretanto, como vimos, ambos pensaram o homem em seus aspectos mais centrais, como o da sua convivência em meio à natureza e de ser ele um ser fundamentalmente político.

A crítica à religião, a antropologia, o elogio à vida em comunidade, a formação do homem político, a alienação dos indivíduos da vida pública e a crítica à opressão dos governos são provas mais do que suficientes de que o pensamento de Rousseau e Feuerbach em muito se aproximam. Além do que, apesar de críticos de seu tempo, ambos mantinham certa esperança na humanidade e no seu potencial de organização política.

Em seu Discurso sobre as Ciências e as Artes, Rousseau (1999b, p. 53) nota que "[...] Os antigos políticos falavam constantemente de costumes e de virtudes, os nossos só falam de comércio e de dinheiro [...]. Avaliam os homens como gados. Segundo eles, um homem só vale para o Estado pelo seu consumo”. Para ele, a política

\begin{tabular}{|c|c|c|c|c|}
\hline Q Rovista Dialectus & Ano 5 & n. 12 & Janeiro - Julho 2018 & p. $209-222$ \\
\hline
\end{tabular}




\title{
RELAĊ̃̃O HOMEM-NATUREZA-POLÍTICA: UM PARALELO... \\ Manoel Jarbas Vasconcelos Carvalho
}

moderna seguiu os caminhos da religião cristã, que trata seu povo como rebanho e vê nele apenas uma forma de acumular poder político.

Somente a liberdade, que é uma relação recíproca entre uma vontade que se autodetermina e a vontade coletiva (geral), pode retirar o homem de um estado de submissão, pois é sob a égide da liberdade que o indivíduo integra-se ao seu fazer político junto aos demais homens. De acordo com Rousseau (2006, p. 372), não há liberdade sem leis e não existe liberdade tendo homens acima delas, visto que a lei deve estar acima de todos e igualmente deve servir a todos:

\begin{abstract}
A liberdade segue sempre o destino das leis. [...] Assim, a liberdade sem a justiça é uma verdadeira contradição, pois não importa o que se pense, tudo constrange na execução de uma vontade desordenada. [...] Um povo livre obedece, mas não serve. Tem chefes, e não senhores. Obedece às leis, mas só a elas, e é pela força das leis que não obedece aos homens.
\end{abstract}

Uma vontade livre, desse modo, é aquela que se autodetermina sob a observação das leis, não estando, com isso, submissa à vontade de outrem, mas autorrealizando-se em confluência com as demais vontades que formam um corpo soberano. Por isso, “[...] em qualquer lugar em que as leis são violadas impunemente, não há mais liberdade" (ROUSSEAU, 2006, p. 331). Ademais, sobre a relação entre uma "vontade individual" e uma "vontade geral", ou entre uma "vontade livre" e a "lei", Rousseau (2006, p. 440) afiança que “[...] só há liberdade possível na observação das leis ou da vontade geral, a vontade geral não quer prejudicar a todos, assim como a vontade particular não quer prejudicar a si mesma".

Feuerbach (2009b) define a liberdade como uma condição de dependência do homem com relação à natureza, que é o fundamento da existência humana, e com relação aos outros homens, que é o fundamento de sua existência na condição de ser social. Consoante Feuerbach (2009b), a verdadeira liberdade só existe quando o homem é livre também religiosamente; a verdadeira cultura só existe quando o homem se torna senhor de seus preconceitos e ficções religiosas.

[...] a meta do Estado não pode ser outra que não formar o homem verdadeiro e completo (completo não no sentido fantástico), por isso um Estado cujos cidadãos não são livres não pode ser um Estado verdadeiramente humano e livre. Não é o Estado que faz o homem, mas os homens que fazem o Estado. Quais homens, tal Estado. (FEUERBACH, 2009b, p. 244).

Assim como Rousseau, Feuerbach é um republicano; ele acredita que é a sociedade civil que deve conduzir o Estado, e não o contrário. Os dois pensadores

\begin{tabular}{|c|c|c|c|c|}
\hline Q Rovista Dialectus & Ano 5 & n. 12 & Janeiro - Julho 2018 & p. $209-222$ \\
\hline
\end{tabular}




\section{RELACÃO HOMEM-NATUREZA-POLÍTICA: UM PARALELO... Manoel Jarbas Vasconcelos Carvalho}

lutaram contra o egoísmo (o individualismo) e contra as facções que permanentemente ameaçaram dividir a soberania popular e tomar o Estado de assalto.

Feuerbach (2009b) julga que a natureza funciona como uma república e que os homens devem imitá-la. O modelo extraído da natureza é a base do republicanismo feuerbachiano. “[...] Em síntese, a natureza é uma república, o resultado dos seres ou forças que se necessitam e criam mutuamente, que trabalham em conjunto, mas que são igualmente capacitados" (FEUERBACH, 2009b, p. 159).

Ao negar os dogmas do Cristianismo e perceber neles uma íntima relação com o autoritarismo dos governos, Rousseau e Feuerbach utilizam uma mesma estratégia: que é a de negar para erigir algo novo. Ao repreenderem o domínio da religião sobre os homens, o que ambos pretendem é afirmar o protagonismo dos indivíduos nas tomadas de decisão políticas. Isso não significa que ambos pretendam destruir a religião, ao contrário, o que os dois querem é manter os seus atributos de amor, solidariedade e respeito ao próximo, mas voltados para o cuidado exclusivo do homem e da natureza.

Sobre esse último aspecto, tanto Rousseau como Feuerbach não acreditam em um retorno da humanidade a um puro estado de natureza. Eles sabem que isso seria impossível no atual nível de desenvolvimento das técnicas e do aperfeiçoamento das instituições sociais. O que eles defendem é que, sob certos aspectos, é possível uma retomada de uma vida mais simples, próxima à natureza e mais participativa politicamente.

Para eles, a política deve ser uma dimensão reconstitutiva do homem com o seu próximo e do homem com a natureza. O ideal do homem político é, portanto, o de um ser recomposto com a natureza, que é o fundamento de sua existência, e com os demais homens, que é a base de sua vida social. Nesse sentido, esse modelo de homem deve estar disposto efetiva e afetivamente à natureza, considerando-a não somente como possuidora da mesma dignidade que ele, mas sobretudo como uma morada para a humanidade.

\section{REFERÊNCIAS}

ARVON, Henri. Feuerbach: sa vie, son oeuvre avec un exposé de sa philosophie. Paris: Universitaires de France, 1964.

\begin{tabular}{|c|c|c|c|c|}
\hline Qenista Dialectus & Ano 5 & n. 12 & Janeiro - Julho 2018 & p. 209-222 \\
\hline
\end{tabular}


BACHOFEN, Blaise. La condition de la liberté: Rousseau, critique des raisons politiques. Paris: Payot, 2002.

CHAGAS, Eduardo Ferreira. A aversão do Cristianismo à natureza em Feuerbach. Philósophos, Goiânia, v. 15, n. 2, p. 57-82, 2010.

A majestade da natureza em Ludwig Feuerbach. In: CHAGAS, Eduardo Ferreira; REDYSON, Deyve; PAULA, Marcio Gimenes de (Org.). Homem e natureza em Ludwig Feuerbach. Fortaleza: UFC, 2009. p. 37-66.

A razão em Feuerbach como base da unidade do homem e da natureza. Princípios, Natal, v. 14, n. 21, p. 215-232, 2007.

CHAGAS, Eduardo Ferreira; REDYSON, Deyve; PAULA, Marcio Gimenes de (Org.). Homem e natureza em Ludwig Feuerbach. Fortaleza: UFC, 2009.

DERATHÉ, Robert. Jean-Jacques Rousseau e a ciência política de seu tempo. São Paulo: Barcarolla: Discurso, 2009.

Le rationalisme de Jean-Jacques Rousseau. Genève: Slatkine, 2011.

DURKHEIM, Émile. Le contrat social de Jean-Jacques Rousseau. Disponível em: $<$ http://classiques.uqac.ca/classiques/durkheim_emile/montesquieu_rousseau/rousseau/r ousseau.html>. Acesso em: 23 set. 2016.

FAGUET, Émile. Rousseau penseur. Paris: Société Française, 1910.

FEUERBACH, Ludwig. A essência do Cristianismo. 2. ed. Petrópolis: Vozes, 2009a.

La esencia de la religión. Madrid: Páginas de Espuma, 2005.

Para a crítica da filosofia de Hegel. São Paulo: LiberArs, 2012.

Preleções sobre a essência da religião. Petrópolis: Vozes, 2009 b.

Princípios da filosofia do futuro. Lisboa: 70, 2002.

Teses provisórias para a reforma da filosofia. In: Princípios da filosofia do futuro. Lisboa: 70, 2002.

GOLDSCHIMDT, Victor. Anthropologie et politique: les principes du système de Rousseau. Paris: J. Vrin, 1983.

GOYARD-FABRE, Simone. Politique et philosophie dans l'oeuvre de Jean Jacques Rousseau. Paris: PUF, 2001.

HAHN, Paulo. Consciência e emancipação: uma reflexão a partir de Ludwig Feuerbach. São Leopoldo: Nova Harmonia, 2003.

MASTERS, Roger D. La philosophie politique de Rousseau. Lyon: ENS, 2002.

\begin{tabular}{|c|c|c|}
\hline Q Rovita Dialectus & Ano 5 & n. 1 \\
\hline
\end{tabular}


MOREL, Jean. Les sources du Deuxième Discours. Annales de la Societé J.-J. Rousseau, Genève, v. 5, p. 119-198, 1909.

PHILONENKO. Alexis. La jeuneusse de Feuerbach. Tome I. Paris: Vrin, 1990.

REDYSON, Deyve; CHAGAS, Eduardo Ferreira (Org.). Ludwig Feuerbach: filosofia, religião e natureza. São Leopoldo: Nova Harmonia, 2011.

RIEU, Alain Marc. La nature de J.-J. Rousseau. Revue de Métaphysique et de Morale, Paris, n. 85, p. 438-451, 1980.

RILEY, Patrick. The general will before Rousseau. Sage, London, v. 6, n. 4, p. 485-516, 1978.

ROUSSEAU, Jean-Jacques. Carta a d'Alembert sobre os espetáculos. In: Obras de Jean-Jacques Rousseau. 1958.

Cartas escritas da montanha. São Paulo: Unesp, 2006.

Discurso sobre a origem e os fundamentos das desigualdades entre os homens (Segundo discurso). São Paulo: Nova Abril Cultural, 1999a.

Discurso sobre as ciências e as artes. São Paulo: Nova Cultural, 1999b.

Do contrato social. São Paulo: Nova Abril Cultural, 1999c.

. Oeuvres complètes. Bibliothèque de la Pléiade: Éd. Bernard Gagnebin \& Marcel Raymond. Paris: Gallimard, 1959-1995. 5 tomos.

SERRÃO, Adriana Veríssimo. A humanidade da razão: Ludwig Feuerbach e o projeto de uma antropologia integral. Lisboa: Calouste Gulbenkian, 1999.

Feuerbach e a apoteose da vida. In: CHAGAS, Eduardo Ferreira; REDYSON, Deyve; PAUlA, Marcio Gimenes de (Org.). Homem e natureza em Ludwig Feuerbach. Fortaleza: UFC, 2009. p. 15-35.

Pensar a sensibilidade: Baumgarten-Kant-Feuerbach. Lisboa: Centro de Filosofia da Universidade de Lisboa, 2007.

SOUZA, Draiton Gonzaga de. $\mathrm{O}$ ateísmo antropológico de Ludwig Feuerbach. Porto Alegre: PUC, 1993.

\begin{tabular}{|l|l|l|l|l|}
\hline Q Ponista Dialectus & Ano 5 & n. 12 & Janeiro - Julho 2018 & p. 209-222 \\
\hline
\end{tabular}

